\title{
Correction to: The clinical significance of fHIT in migraine patient without vertigo symptom
}

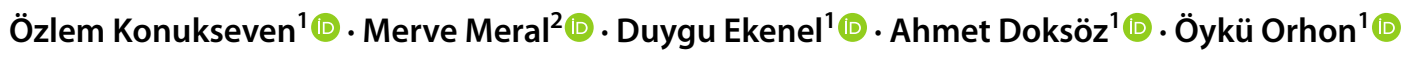

Published online: 5 May 2021

○) Springer-Verlag GmbH Germany, part of Springer Nature 2021

\section{Correction to:}

European Archives of Oto-Rhino-Laryngology https://doi.org/10.1007/s00405-021-06811-8

In the original publication of the article, under the section "Material and methods", the following sentence "This study was conducted in the clinical laboratory of the Audiology Department of Istanbul Aydin University from January-May 2019. It was approved by the Istanbul Aydin University NonInterventional Clinical Research Ethics Committee (registration number 2019/118) on June 19th, 2019." was published incorrectly. January-May months should be changed to July-December.
Hence, the correct sentence should read as follows, "This study was conducted in the clinical laboratory of the Audiology Department of Istanbul Aydin University from July-December 2019. It was approved by the Istanbul Aydin University Non-Interventional Clinical Research Ethics Committee (registration number 2019/118) on June 19th, 2019."

In addition, the figure 1 was published incorrectly and correct Fig. 1 is provided below.

The original article was updated.
The original article can be found online at https://doi.org/10.1007/ s00405-021-06811-8.

\section{Merve Meral}

mervemeral1@aydin.edu.tr

Özlem Konukseven

ozlemkonukseven@aydin.edu.tr

Duygu Ekenel

duyguekenel@stu.aydin.edu.tr

Ahmet Doksöz

ahmetdoksoz@stu.aydin.edu.tr

Öykü Orhon

oykuorhonn@hotmail.com

1 Department of Audiology, Faculty of Health Sciences, Istanbul Aydin University, Istanbul, Turkey

2 Audiometry Program, Vocational School of Health Services, Istanbul Aydin University, Istanbul, Turkey 

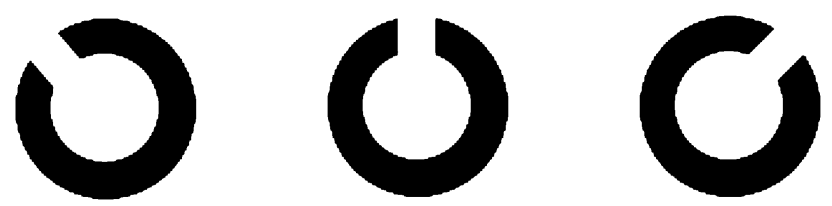

Publisher's Note Springer Nature remains neutral with regard to jurisdictional claims in published maps and institutional affiliations.
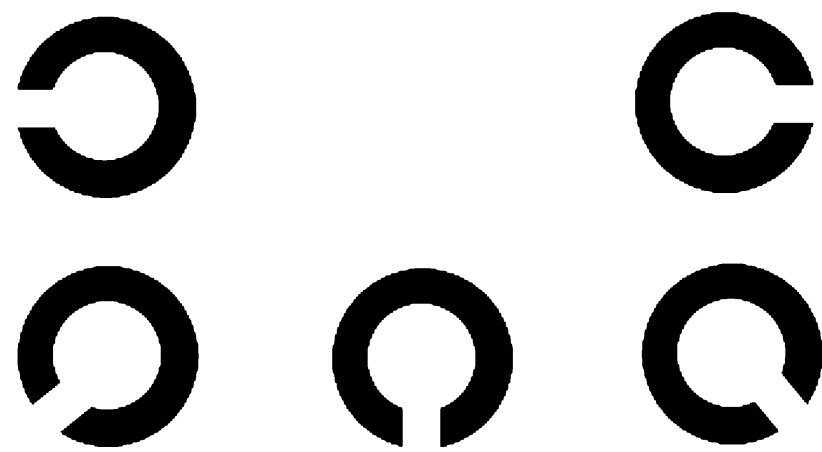

Fig. 1 Landolt C Optotype examples are seen on the test screen 